\title{
The "Colour Family Drawing Test": Assessing Children's Perception of Family Relationships. Studies on Mental Health and Cross-Cultural Comparisons
}

\author{
Valeria Biasi' ${ }^{1}$, Paolo Bonaiuto² ${ }^{2}$ James M. Levin ${ }^{3}$ \\ ${ }^{1}$ Department of Education, "Roma Tre" University, Rome, Italy \\ 2Department of Psychology, "Sapienza" University of Rome, Rome, Italy \\ ${ }^{3}$ John Jay College, City University of New York, New York, USA \\ Email: valeria.biasi@romascuola.net, paolo.bonaiuto@uniroma1.it, jameslevin@msn.com
}

Received 10 February 2015; accepted 5 March 2015; published 10 March 2015

Copyright (C) 2015 by authors and Scientific Research Publishing Inc.

This work is licensed under the Creative Commons Attribution International License (CC BY). http://creativecommons.org/licenses/by/4.0/

(c) (i) Open Access

\section{Abstract}

We apply the Colour Family Drawing Test, as a development of the traditional black and white test, for cross-cultural comparison. The participants, aged 7 - 10 years, both genders, were examined individually. Each subject sat at a single table with a white rectangular card of standard size, 24 well-sharpened colour pencils, a black pencil, an eraser and other appropriate tools. $S /$ he received this verbal instruction: "Draw your family". The procedure was firstly applied to 120 participants attending primary schools of Rome (Biasi, Bonaiuto and Levin, 2014). The families were evaluated through a semi-structural interview conducted with the children's teachers and divided into: Harmonious versus Very Conflictual Families. The drawings made by children of Harmonious Families consistently used "Reassuring and Playful Colours" (Pink, Orange, Sky Blue, Light Green, Light Yellow, other pastel colours); and were larger, tidier and more proportioned to respect the opposite group. Children belonging to Conflictual Families used mostly "Alarming and Serious Colours" (Grey, Black, Dark Bleu, Violet, Olive Green) and their drawings were less extended, more often disordered and had typical deformations such as figures too thin. A second investigation examined 120 participants belonging to Asian immigrant families residing in Italy. A third investigation examined 120 participants belonging to Russian families of Moscow. Both last two investigations obtained very similar results on the use of colours, and gave a confirmation of the relevance of the Colour Family Drawing Test.

\section{Keywords}

Colour, Conflictual Family, Cross-Cultural Comparison, Colour Drawing Family Test, 


\section{Expressiveness}

\section{Introduction}

The Family Drawing Test was generally performed with children for the assessment of cognitive and emotional development, as indicators of mental health, and for the evaluation of children's perceptions of family relationships.

Recently, the research is oriented to the analysis of attachment styles in relation to Family Drawing characteristics, also related to main personality traits of parents or caregivers.

Arteche, \& Murray [1] investigated the effects of maternal postnatal depression and anxiety on children's family representations. In a sample of postnatally depressed mothers, family drawings of 235 children 4 - 5 year-old were examined. When compared to controls, children of depressed mothers, were more likely to draw themselves as less prominent than other family members and to represent a dysfunctional family, less likely to represent themselves with a happy face and showed a greater tendency of drawing bizarre pictures.

Goldner and Scharf [2] examined the relationship between children's attachment security, as manifested in their family drawings, and their personality and adjustment. Family drawings were collected from 222 Israeli children, as well as data regarding their personality and adjustment. Results showed that drawings from securely attached children included more positive markers such as completeness of figures, facial expression, size, and degree of movement.

Drawings from children in the ambivalent and disorganized attachment categories reflected the children's adjustment difficulties; children whose drawings were classified as representing avoidant attachment were found to function relatively well. The study demonstrated the effectiveness of using family drawings to assess children's attachment representations and to identify children at risk for adjustment problems in the school setting.

Gorman [3] examined the distribution of attachment patterns using family drawings in a middle childhood community sample. Significant associations were found between child gender, maternal income and maternal marital status, and attachment patterns in family drawings; child male gender and maternal single status were both associated with higher rates of disorganization and insecurity, while female gender and maternal married status were associated with higher rates of organization and security. Results of this study provide support for the use of Family Drawings as a valid measurement of attachment in middle childhood, specifically in high-risk and ethnically diverse samples.

Gernhardt, Rübeling and Keller [4] examined the Family Drawings of preschool-aged children from three cultural contexts (middle-class families from Osnabrueck, Germany; from rural Cameroonian and from Ankara, Turkey) that represented different aspects of autonomy and relatedness, specifically in regard to the number and position of family members, the depicted absolute and relative size of family members, and the details of facial features.

Generally, the Family Drawing Test is applied in all this studies in a black and white version and for this reason this procedure has lost, according to us, the possibility to collect very important informations: such as the level of emotional conflict that can be expressed by the use of colours, expecially by children.

In any case, when occasionally authors included the use of colours, they didn't utilize specific indicators for colour evaluation: such as the emotional quality of the colour and the colour meaning. For this reason our research group introduced some years ago, a classification of indicators of graphic pictorial language linked to conflictual meanings - or harmonious ones_derived from research study on psychology of expressiveness, as we will explain below.

\section{The Colour Family Drawing Test}

\subsection{First Investigation: The Italian Sample}

First, confirm that you have the correct template for your paper size. This template has been tailored for output on the custom paper size $(21 \mathrm{~cm} * 28.5 \mathrm{~cm})$. The classic "Family Drawing" procedure, as established by Corman (1964) [5] constantly envisages black and white drawings. However this author mentioned the possibility of using "also coloured pencils", and there was a short attempt in this sense by Abegg (1973) [6]. 
On the basis of a series of previous observations conducted by Biasi \& Bonaiuto (2005) [7], Biasi, Bonaiuto and Levin (2014) [8] applying the Colour Family Drawing Test to a large sample of children from 7 to 10 years.

According to this procedure each participant is individually examined, sitting at the table with an A4-format rectangular card $(35 \times 25 \mathrm{~cm}$ ), a set of 24 well-sharpened coloured pencils, a black pencil, a black thin tipped felt-tip pen, an eraser and a pencil sharpener. The following instruction is given orally: "Draw your family" (a sentence used also by Appel [9]; Porot [10] [11]; Cain \& Gomilla [12]; Fukada [13]).

In the first study this new procedure was applied to 120 subjects (both genders), aged 7 - 10 years and living in Rome, belonging to Italian families and attending primary school of the city [8]. These families where divided into two groups, on the basis of information given by the teachers throw a semistructured interview:

1) Harmonious Families, characterised by supportive parents, who can guarantee affective support, maintaining harmonious interpersonal relations.

2) Very Conflictual Families, characterised by a high degree of parental conflict, expressions of open violence within the family, difficult separation or divorce either underway or imminent [14]-[16], the presence of other partners with negative characteristics, a parent that is hardly present due to some serious impediment such as imprisonment, drug-addiction, grave illness, etc.

As regards graphic pictorial language Biasi, Bonaiuto and Levin [8] found that the children belonging to Very Conflictual Families mostly used in their family depictions "Allarming and Serious Colours" (Grey, Black, Violet, Dark Blue, Olive Green) instead of the "Reassuring and Playful Colours" (Pink, Orange, Pastel Hues), typical of the children belonging from Hamonious Families.

Furthermore, the children of Very Conflictual Families used mainly angular shapes and broken lines instead of rounded shapes and continuous lines, preferred by the children of the opposite category. The drawings of children of Very Conflictual Families were also significantly less accurate, more irregular and deformed, while the drawings of the children belonging to the Harmonious category were more accurate, regular and well shaped and these last dates confirm the previous specific literature [5] [11] [17] [18].

Note that the graphic abilities are generally represented as normal distribution, so this variables don't enable the results with quite large sample.

Children belonging to Conflictual Families (Figure 1(a) and Figure 1(b)) used mostly "Alarming and Serious Colours" (Grey, Black, Dark Bleu, Violet, Olive Green) and their drawings were less extended, more often disordered and had typical deformations such as figure slimness.

The drawings made by children of Harmonious Families (Figure 2(a) and Figure 2(b)) consistently used Reassuring and Playful Colours” (Pink, Orange, Sky Blue, Light Green, Light Yellow, other pastel colours); and were larger, tidier and more proportioned to respect the opposite group.

\subsection{Second Investigation: The Asian Sample}

The graphic-pictorial test was applied in Rome in a second study, with children of immigrant Families [19]. This second investigation examined 120 participants belonging to Asian immigrant families residing in Italy (from Bangladesh, China, Pakistan, Philippines and other countries).

The comparisons with the Italian data proved that quite similar graphic-pictorial languages are used, with some minor but interesting and meaningful differences.

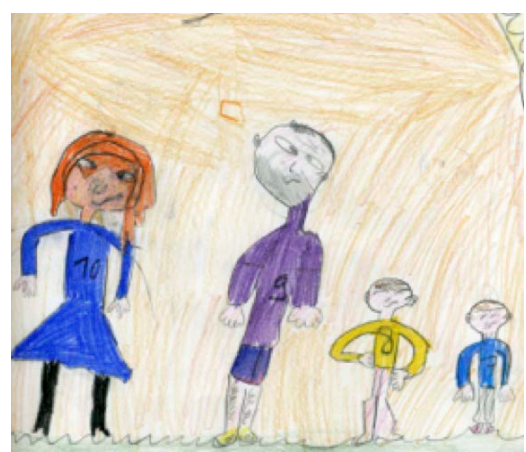

(a)

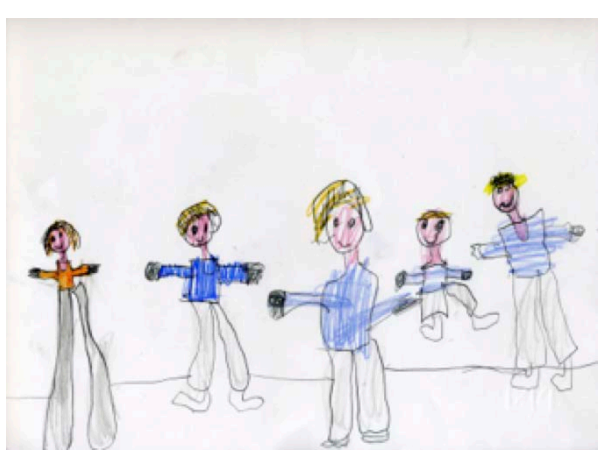

(b)

Figure 1. Colour family drawing by Italian children of "very conflictual families". 


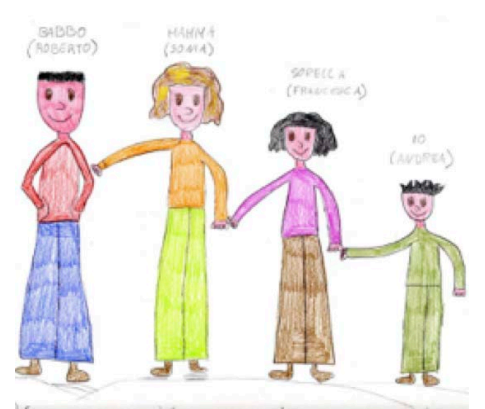

(a)

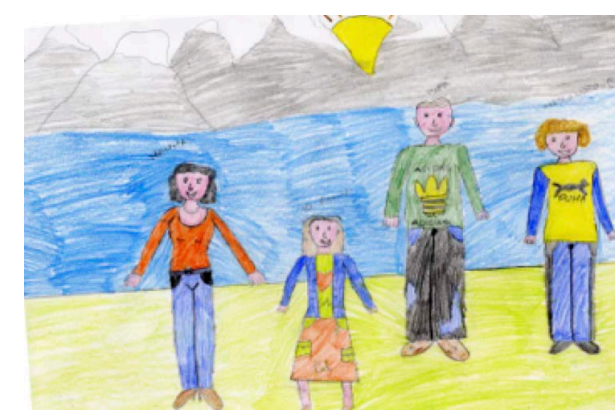

(b)

Figure 2. Colour family drawing by Italian children of "harmonious families".

Also these families where divided into two groups, on the basis of information given by the teachers throw a semistructured interview: the Harmonious Families versus Very Conflictual ones. Again, children of Very Conflictual Families generally used "Alarming and Serious Colours" in their drawings (Figure 3(a) and Figure $3(\mathrm{~b}))$.

Those of Harmonious Families typically used "Reassuring and Playful Colours" (Figure 4(a) and Figure 4(b)). As in the previous investigations, the first category includes parents who can guarantee affective support, maintaining harmonious interpersonal relations.

The opposite category is again characterized by a high degree of parental conflict, expressions of open violence within the family, difficult separation, extreme poverty, etc.

Drawings of the first type were significantly less accurate, more irregular and deformed, with figure slimness as another typical indicator; those of the opposite category were clearly more accurate and proportionate; and used more space.

The second investigation had very similar results to the previous ones, except for more accuracy shown by Asian children of Harmonious Families.

\subsection{Third Investigation: The Russian Sample}

Another investigation was then planned and performed [20]. Again, 120 participants were examined: Russian children living in Moscow, engaged in Moscow Elementary Schools, also divided into two groups - children of Harmonious and Very Conflictual families, such as in the other cultures.

The research procedure remained the same.In the results, the general relations between colours and emotional meanings turned out as in the previous investigations, with some peculiarities.In the drawing of the conflictual group (Figure 5(a) and Figure 5(b)): the absence of colours, that is, the use of the black and white drawing style, was more frequent, together with the use of black contours.

The drawings belonging to the harmonious group are frequently represented with reassuring and playful colours (Figure 6(a) and Figure 6(b)).

As we can see in Table 1, the comparison of the results obtained showed a quite similar distribution of the colours in "Alarming and Serious" versus "Playful and Reassuring" in the three groups of children interviewed (Italian, Asian and Russian), according to the level of family psychological conflict. This frequency percentage are calculated on the basis of 80 drawings for groups (respectively 40 belonging from Conflictual Families and 40 from Harmonious Families). Drawings represented with mixed colours are not included.

Moreover, some peculiarities appear: for examples in the Asian sample of Family Drawing we can see more accuracy and particularly attention is devoted to the representation of details.

\section{Discussion and Conclusions}

The phenomenal properties of colours were initially studied by Koffka [21], Metzger [22], and underlined by Gibson [23], with the concept of "affordances".

Collected data-from experimental and clinical setting—confirm that, on the whole, the "Alarming and Serious" colours turned out to be violet, grey, black, dark blue and olive green, possibly including red and yellow stripes, while the so-called "Reassuring and Playful" colours were mainly hues of pink as well as orange, sky 


\section{e⿻日木}

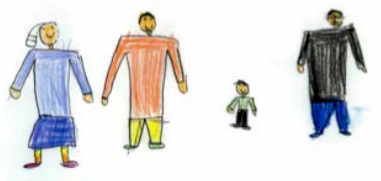

(a)

(b)

Figure 3. Colour family drawing by Asian children of "very conflictual families”.

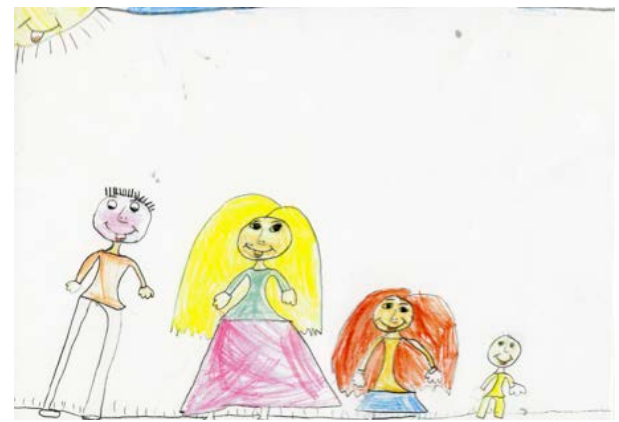

(a)

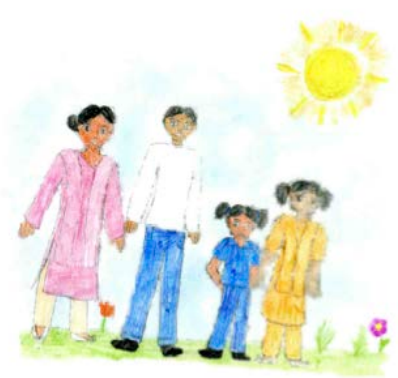

(b)

Figure 4. Colour family drawing by Asian children of "harmonious families".

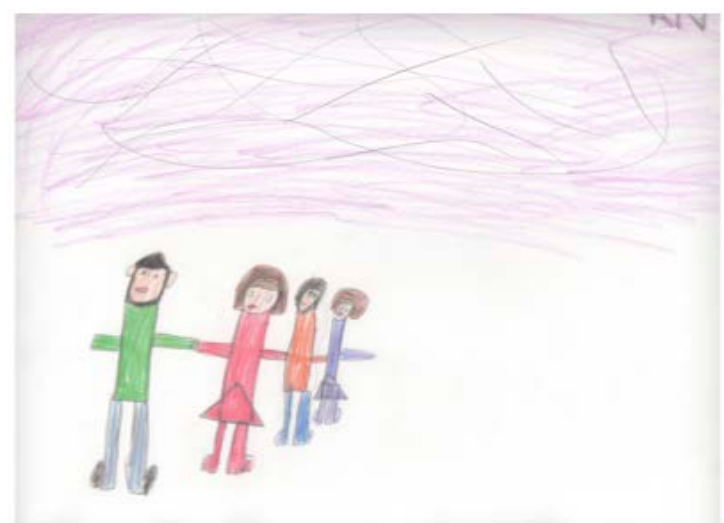

(a)

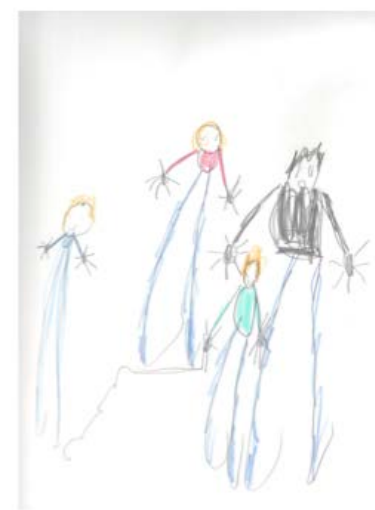

(b)

Figure 5. Colour family drawing by Russian children of "very conflictual families”.

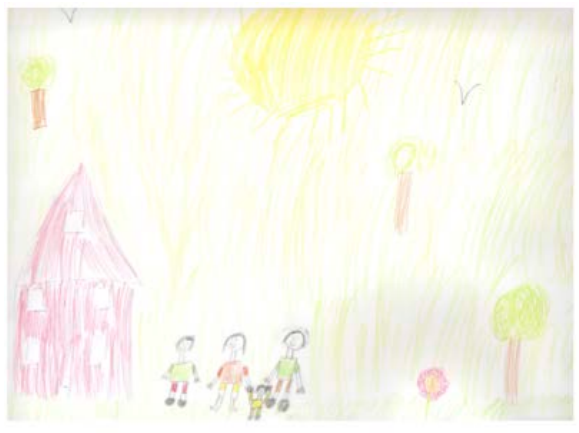

(a)

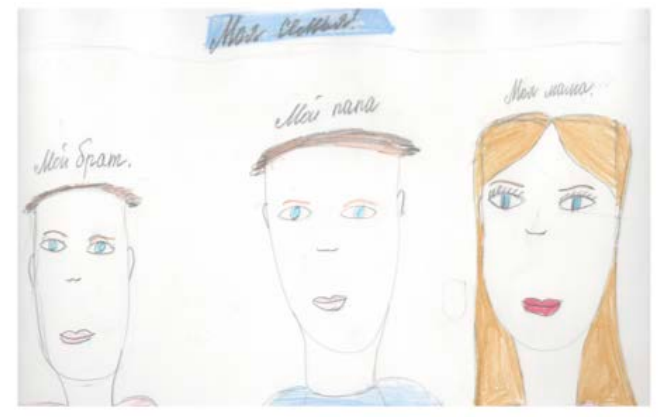

(b)

Figure 6. Colour family drawing by Russian children of "harmonious families". 
Table 1. Frequency percentage of colours used by children belonging to "very conflictual families” versus children belonging to "harmonious families", in three different countries (Italy, Asia and Russia).

\begin{tabular}{cccc}
\hline \multirow{2}{*}{ Colours } & \multicolumn{3}{c}{ Colours Family Drawings } \\
\cline { 2 - 4 } & From Conflictual Family (n= 40) & From Harmonious Family (n= 40) & Nationality \\
\hline Alarming and Serious Colours & $10(\mathbf{2 5 \% )}$ & $1(2.5 \%)$ & Italian Sample \\
Playful and Reassuring Colours & $5(12.5 \%)$ & $18(\mathbf{4 5 \% )}$ Asian Sample Italian Sample \\
Alarming and Serious Colours & $12(\mathbf{3 0 \%})$ & $6(15 \%)$ & Russian Sample Italian Sample \\
Playful and Reassuring Colours & $4(10 \%)$ & $16(\mathbf{4 0 \% )}$ & $5(2.5 \%)$ \\
Alarming and Serious Colours & $17(\mathbf{4 2 . 5 \% )}$ & $15(\mathbf{3 7 . 5 \% )}$ & \\
\hline
\end{tabular}

blue, light green, light yellow and other pastel colours.

Following the Natural Colour System (NCS) [24], the "Alarming and Serious" colours correspond to specific codes. For example, Olive-Green is 10 30-R60B.

The "Reassuring and Playful" colours also correspond to specific codes; for example, Orange is 05 85-Y60R. These labels are useful to clearly identify the tonalities.

Moreover, the emotional meaning of these hues is registered and detected by using bipolar scales with contrasting adjectives, such as "Alarming”, "Serious", Disquieting”, "Reassuring”, "Playful”, etc.

Bonaiuto in 1978 [25] introduced a distinction between "Alarming and Serious" colours and "Reassuring and Playful" ones. Others studies followed on the illustrations of fairytales and comics, firstly investigated in an occasional manner, and then in a rigorously systematic way [26]. In other words, these studies make a connections between colour hues and emotional meanings, as illustrated by the systematic distinction made between "Alarming and Serious" colours as opposed to "Reassuring and Playful" ones.

This distinction was also confirmed through experimental works dealing the results of so-called procedures of "Stress Drawing” and “Comfort Drawing” [27] [28].

In other studies carried out by Bonaiuto, Giannini, Biasi, Miceu Romano and Bonaiuto [29], it was confirmed that alarming and serious colourations produced an increase of conflict perception that generate phenomena of perceptual defence, while reassuring and playful hues favoured a decrease of conflict and a phenomena of acceptance and facilitation of incongruities. This research group demontrated also that some defence effects were obtained in the perception of conflictual images such as architectural incongruities under the influence of alarming colours. So, to the structural conflict typical of an architectural incongruence, the authors added a further conflictual atmosphere, given by the use of widespread colourings of an "alarming and serious" kind (greyviolet or olive green); opposite effects were obtained with "reassuring and playful" colours (bright pink or orange).

Perceptual defence phenomena is linked to the overload of psychological conflict as demonstrated in the classical clinical observations [30], such as in the classical experimental studies conducted by functionalists through the presentation of taboo words [31] or words and pictures linked to previous painful experiences [32]. In these circumstances, there was a significant delay in recognising these elements in tachystoscopic presentations. This delay was interpreted as a manifestation of defence in perception [33].

On the basis of these observations, we underline important connections between phenomenology and psychodynamics, with the support of experimental confirmations. This approach appears useful for clinical applications, as in the case of the projective test of Colour Family Drawing. Finally, we discovered that the use of disquieting hues is linked to psychological conflict overload that generally arouses psychological defence.

The comparison of the results obtained showed a quite similar distribution of the colours in "Alarming and Serious" versus "Playful and Reassuring" in the three groups of children interviewed (Italian, Asian and Russian), according to the level of family psychological conflict. This frequency percentage are calculated on the basis of 80 drawings for groups (respectively 40 belonging from Very Conflictual Families and 40 from Harmonious Families).

Moreover, some peculiarities appears: for examples in the Asian sample of Family Drawing, we can see more 
accuracy and particularly attention to the representation of details.

In conclusion, the laws of colour expressiveness reveal considerable overall cross-cultural stability.

\section{References}

[1] Arteche, A. and Murray, L. (2011) Maternal Affective Disorder and Children's Representation of Their Families. Journal of Child and Family Studies, 20, 822-832. http://dx.doi.org/10.1007/s10826-011-9450-7

[2] Goldner, L. and Scharf, M. (2011) Children's Family Drawings: A Study of Attachment, Personality, and Adjustment. Art Therapy, 28, 11-18. http://dx.doi.org/10.1080/07421656.2011.557350

[3] Gorman, H.R. (2012) Family Drawings and Self-Reported Attachment in Children of Trauma-Exposed Mothers. The Sciences and Engineering, 173. www.proquest.com/products-services/pqdt.html

[4] Gernhardt, A., Rübeling, H. and Keller, H. (2013) “This Is My Family”: Differences in Children's Family Drawings across Cultures. Journal of Cross-Cultural Psychology, 44, 1166-1183. http://dx.doi.org/10.1177/0022022113478658

[5] Corman, L. (1964) The Family Drawing Test in Medical-Pedagogical Practice. P.U.F, Paris.

[6] Abegg, W. (1973) Der Familientest. Werner Classen, Zurich.

[7] Biasi, V. and Bonaiuto, P. (2005) Experimental Graphic-Pictorial Representation of Harmonious or Conflictual ParentChild Relations. "Sapienza” University of Rome, Rome.

[8] Biasi, V., Bonaiuto, P. and Levin, J. (2014) The "Colour Family Drawing Test”: A Comparison between Children of "Harmonious” or "Very Conflictual Families". Psychology, 5, 2099-2108. http://dx.doi.org/10.4236/psych.2014.519212

[9] Appel, L. (1931) Drawings of Children as Aids to Personality Study. American Journal of Orthopsycology, 10, 815828.

[10] Porot, M. (1952) The Family Drawing. Exploration through Drawing of the Affective Situation of Children in Their Family. Pédiatrie, 3, 359-381.

[11] Porot, M. (1965) The Family Drawing. Revue de Psychologie Appliquée, 3, 77-89.

[12] Cain, J. and Gomilla, J. (1953) The Infant’s Family Drawing: Classification Criteria. Annales Médico-Psychologiques, 5, 502-506.

[13] Fukada, N. (1958) Family Drawing by School Children. Japanese Journal of Psychology, 29, 264-267. http://dx.doi.org/10.4992/jjpsy.29.264

[14] Hulse, W.C. (1951) The Emotionally Disturbed Child Draw His Family. The Quarterly Child Behavior, 3, 152-174.

[15] Spigelman, G., Lungs, U., Sweden Spigelman, A. and Englesson, I.L. (1993) Analysis of Family Drawings: A Comparison between Children from Divorce Families. Journal of Divorce and Remarriage, 18, 31-54. http://dx.doi.org/10.1300/J087v18n01_02

[16] Roe, A.E.C., Bridges, L.J., Dunn, J. and O'Connor, T.G. (2006) Young Children’s Representations of Their Families: A Longitudinal Follow-Up Study of Family Drawings by Children Living in Different Family Settings. International Journal of Behavioral Development, 30, 529-536. http://dx.doi.org/10.1177/0165025406072898

[17] Comunian, A.L. (1984) Contribution to the Experimental Study of Projective Techniques: Dynamics Emerging from the Cluster Analysis of Family Drawing. Psicologia Clinica, 3, 97-119.

[18] Biasi, V., Bonaiuto, P. and Levin, J. (2015) Relation between Stress Conditions, Uncertainty and Incongruity Intolerance, Rigidity and Mental Health: Experimental Demonstrations. Health, 7, 71-84. http://dx.doi.org/10.4236/health.2015.71009

[19] Bonaiuto, P., Longo, S., Biasi, V., Borsellino, F. and D’Aloise, D. (2011) Colour Family Drawings Produced by Children of Asian Cultures. Proceedings of the 10th International Symposium on Measurement Technology and Intelligent Instruments (ISMTII 2011), Daejeon, 29 June-2 July 2011, D7-4, CD-Rom, 4.

[20] Biasi, V., Kormakova, D., D’Aloise, D., Longo, S., Siervo, G. and Stoica, L. (2011) The Colour Family Drawing. Sources and Applications. In: Rossi, M., Ed., Colour and Colorimetry: Multidisciplinary Contributions, Maggioli Editore, Santarcangelo di Romagna (Rimini), Vol. VII/B, 191-195.

[21] Koffka, K. (1935) Principles of Gestalt Psychology. Harcourt Brace, New York.

[22] Metzger, W. (1954) Psychologie. Steinkopf, Darmstadt. http://dx.doi.org/10.1007/978-3-662-43003-3

[23] Gibson, J.J. (1979) The Ecological Approach Tool Visual Perception. Houghton Mifflin, Boston.

[24] Scandinavian Colour Institute (2004) NCS. Natural Color System. Scandinavian Colour Institute, Stockholm.

[25] Bonaiuto, P. (1978) Forme Lineari e Bande Colorate. Un reattivo per la valutazione delle capacità di percepire l'espressività visuale. First University of Rome "La Sapienza”, Rome. 
[26] Biasi, V. and Bonaiuto, P. (2006) The Graphic-Pictorial Language of Stress (Conflict) and Comfort (Agreement) in Fairy Tale Illustrations. In: Gottesdierner, H. and Vilatte, J.C., Eds., Culture and Communication, IAEA, Avignon, 473-477.

[27] Biasi, V. and Bonaiuto, P. (1997) Colour and the Experimental Representation of Stress and Comfort. In: Sivik, L., Ed., Colour \& Psychology, Scandinavian Colour Institute, Stockholm, 54-65.

[28] Biasi, V., Bonaiuto, P. and Giannini, A.M. (2007) Emotional Qualities and Valences of Colours: A Review of Experimental Demonstrations. In: Rizzi, A., Ed., Colore e Colorimetria: Contributi Multidisciplinari, Centro Editoriale Toscano, Florence, Vol. 3, 183-194.

[29] Bonaiuto, P., Giannini, A.M., Biasi, V., Miceu Romano, M. and Bonaiuto, M. (1996) Visual Defense or Facilitation Processes Favored by Alarming or Playful Colours. In: Dickinson, C.M., Murray, J. and Carden, D., Eds., John Dalton’s Colour Vision Legacy, Taylor \& Francis, London, 723-731.

[30] Freud, S. (1990) Die Traumdeutung. Deuticke, Leipzig.

[31] McGinnies, E.M. (1949) Emotionality and Perceptual Defense. Psychological Review, 56, 244-251. http://dx.doi.org/10.1037/h0056508

[32] Postman, L., Bruner, J.S. and McGinnies, E.M. (1946) Personal Values and Selective Factors in Perception. Journal of Abnormal and Social Psychology, 43, 142-154. http://dx.doi.org/10.1037/h0059765

[33] Bruner, J.S. and Postman, L. (1949) On the Perception of Incongruity: A Paradigm. Journal of Personality, 18, 206223. http://dx.doi.org/10.1111/j.1467-6494.1949.tb01241.x 